\title{
Negative views of out-groups and emotion regulation strategies: Evidence for an association with the tendency to suppress emotion expression, but not with cognitive reappraisal or emotion dysregulation
}

\author{
Minja Westerlund ${ }^{1}$ (D) $\cdot$ Jan Antfolk ${ }^{1} \cdot$ Pekka Santtila $^{2}$ \\ Published online: 9 October 2019 \\ (C) The Author(s) 2019
}

\begin{abstract}
Emotions influence attitudes and appraisals toward out-groups, including prejudice. We hypothesized that individuals who successfully regulate emotions will express more positive attitudes toward out-groups. We conducted an online study of associations between emotion regulation and attitudes toward out-groups in a Finnish population-based sample $(N=320)$. As hypothesized, expressive suppression was associated with decreased acceptance toward out-groups, but contrary to our hypothesis, cognitive reappraisal was not associated with increased acceptance. In exploratory analyses, we found that individuals with more cognitive reappraisal (vs. expressive suppression) had a higher acceptance of out-groups, and that emotion regulation may not influence attitudes toward all out-groups equally. In conclusion, we present novel results indicating that habitual emotion regulation strategies are differently associated with attitudes toward a broad array of out-groups, and that the sociocultural aspects of emotion regulation toward out-group attitudes may play a role.
\end{abstract}

Keywords Emotion regulation $\cdot$ Expressive suppression $\cdot$ Cognitive reappraisal $\cdot$ Prejudice $\cdot$ Out-groups

During the recent decade, there has been a surge in public antiimmigration rhetoric and attitudes in Europe (Vieten and Poynting 2016). This phenomenon of intergroup hostility has traditionally been examined focusing on cognitive representations and processes (Miller et al. 2004). However, when observing intense intergroup interactions, such as rallies between rivalling political groups, it is evident that also emotions play an important role in out-group attitudes. We assessed whether the ability to successfully regulate those emotions is associated with decreased negative attitudes toward out-groups. If modifying emotional responses is related to increased intergroup acceptance, it could constitute a

Electronic supplementary material The online version of this article (https://doi.org/10.1007/s12144-019-00430-7) contains supplementary material, which is available to authorized users.

Minja Westerlund

minja.westerlund@abo.fi

1 Åbo Akademi University, Turku, Finland

2 New York University, Shanghai, China significant complement to programs and interventions aimed at decreasing intergroup hostility.

Emotions and cognitions are closely interrelated (Scherer 2009; Blanchette and Richards 2010; Izard 2010). This is reflected in certain central theories of out-group attitudes that include affective components (e.g. Zawadzki 1948; Allport 1985), and especially in appraisal theories of emotions (discussed in Moors et al. 2013), which posit that emotional reactions depend on the individual's interpretation of the situation. Emotions again activate certain appraisal tendencies, which are relatively automatic and steer the following perceptions and decision-making (Lerner and Keltner 2000). For example, if an individual perceives that an out-group is unjustifiably receiving better social services than the group he or she identifies with, the emotional reaction can be anger. This negative emotion may then affect subsequent out-group related emotions, appraisals and attitudes (Halperin and Gross 2010). Previous literature has indeed linked emotions to prejudice. For example, Tenenbaum et al. (2018) conducted an experiment in a sample of British young people where they induced positive or negative emotions through a written emotion recall manipulation, and later measured attitudes toward asylum seekers' rights and feelings toward asylum seekers. The authors found 
that inducing positive emotions increased acceptance toward asylum seekers. Miller et al. (2004) showed in two survey studies among white college students that emotions predicted prejudice toward out-groups, and that emotions mediated the relationship between prejudice and intergroup contact, and political predispositions, respectively. Similarly, Kessler et al. (2010) found in a large longitudinal, two-wave panel survey study of German 13-18 year old pupils that positive intergroup emotions were negatively related to a variety of prejudice measures. Also Tapias et al. (2007) found support for the association between prejudice and specific emotions toward out-groups among university students in two studies; a survey study and a study in which the participants were first exposed to outgroup priming, after which their reactions to stories designed to elicit different negative emotions were assessed.

The way an individual appraises a situation (or, in this case, an out-group) is, apart from emotional processes, also affected by several other, non-affective factors (Halperin et al. 2011). These include cultural (Moors et al. 2013), situational (Smith and; Kirby 2009) and intersectional factors (Wang et al. 2011), as well as personality and socio-economic status (Halperin et al. 2011). A thorough discussion of these factors is, however, beyond the scope of the present paper.

\section{Emotion Regulation and Out-Group Attitudes}

Humans are not merely passive emitters of emotion, but can actively affect their emotional experience (Mauss et al. 2007). The term emotion regulation refers to how individuals influence their own emotional state; what emotions they have, when, and how they experience and express them (Gross 1998). Since emotions are strongly associated with prejudice, we expected that modifying and regulating those emotions will be associated with an alteration of attitudes toward out-groups.

As described by Aldao (2013), emotion regulation strategies are often categorized into adaptive and maladaptive strategies based on their relationship with psychopathology symptoms. However, adaptive emotion regulation may imply different things in different settings, and whether or not emotion regulation strategies are adaptive depends in the end on contextual factors (Aldao 2013): for example, depending on individual and situation characteristics (e.g., Nolen-Hoeksema and Aldao 2011; Pliskin et al. 2018), the interaction between different emotion regulation strategies (Nolen-Hoeksema and; Aldao 2011; Aldao and Nolen-Hoeksema 2013), and probably also on the type of emotion regulation measured (habitual or instructed emotion regulation; Wolgast et al. 2011). Also, stress may compromise the ability to adaptively regulate emotions (Raio et al. 2013). Given the importance of contextual factors, Aldao (2013) recommends specifying the components that affect emotion regulation when conducting research in order to gain a broader understanding of the factors affecting the process. In the current paper, as we discuss next, we used a survey study to investigate the associations between trait-level emotion regulation and attitudes toward out-groups. We focused on two important emotion regulation strategies: cognitive reappraisal and expressive suppression.

Cognitive Reappraisal Involves reassessing a situation, changing its meaning, and thereby modifying its emotional impact (Gross 1998). For example, if an out-group member avoids eye contact during a conversation, the discussion partner may interpret the behaviour as rude and feel annoyance as a result. However, if the person cognitively reappraises the situation by thinking that the out-group member acts according to their cultural norms without an intention of insulting, the negative emotion is likely to be downregulated. This emotion regulation strategy has been found to effectively reduce negative emotions and increase positive emotions (Gross and John 2003; Nezlek and Kuppens 2008) and it is generally considered an adaptive form of emotion regulation and has been linked to less psychopathology (Aldao et al. 2010, but see also NolenHoeksema and; Aldao 2011). It is thus likely that individuals who habitually use more cognitive reappraisal experience a lesser magnitude of negative emotions and thereby less negative emotions also toward out-groups. Since emotions trigger a tendency to perceive and appraise objects and situations in a way that is consistent with the original appraisal-patterns of that emotion (Lerner and Keltner 2000), decreased negative out-group emotions would likely result in more tolerant attitudes toward out-groups. Indeed, previous studies suggest that cognitive reappraisal is associated with more positive attitudes toward out-groups. Halperin and Gross (2011) found in a nationwide survey that among Israelis, after controlling for sociopolitical variables, the use of cognitive reappraisal was positively associated with support for humanitarian aid for Palestinians. In another survey study using a representative sample, Halperin and colleagues (Halperin et al. 2014) reported a negative correlation between the use of cognitive reappraisal and political intolerance in Israeli citizens during the 2009 Gaza war. Further, investigating causal effects in a sample of students, the authors found that, when participants prone toward political intolerance were instructed to use cognitive reappraisal while reading a news article prompting intolerance, both their negative emotions and intolerance decreased compared to a control condition. Similarly, Halperin et al. (2013) found in a laboratory study with a sample of Israeli university students that applying cognitive reappraisal after a brief training in response to anger-inducing material decreased the level of anger toward Palestinians and decreased support for aggressive policies. Similar findings were presented in a second study that included a 5-month follow-up assessment. Alkoby et al. (2017) found that among Jewish-Israelis, an 8-13 week mindfulness training and a brief cognitive reappraisal training (both individually and combined) increased the 
support for compromise solutions of the Israel-Palestinian conflict, compared to a waitlist control. The effect was mediated by a reduction in negative emotions toward Palestinians. Relatedly, Lee et al. (2013) found in survey studies among US participants that cognitive reappraisal was negatively associated with support for conservative policies, and that it also decreased moral concerns related to conservatism by reducing the emotion of disgust. The authors suggest that the results may transfer into political attitudes, for example, regarding immigration and gay marriage.

There are also findings indicating that different emotion regulation strategies interact, and it is thus motivated to consider not only individual emotion regulation strategies, but also their relation to each other. Aldao and Nolen-Hoeksema (2012) found that cognitive reappraisal and other adaptive emotion regulation strategies had a negative association with psychopathology only when the level of maladaptive strategies was high. Results in the same direction have been reported by Otterpohl et al. (2016). See also Bonanno and Burton (2013) for a discussion on regulatory flexibility.

Expressive Suppression. The other well-researched form of emotion regulation is expressive suppression, which involves inhibiting the expression of an emotional response (Gross 1998). In contrast to cognitive reappraisal, expressive suppression has been associated with increased or prolonged duration of negative emotions (Gross and John 2003; Nezlek and Kuppens 2008), likely because whereas expressive suppression effectively decreases the expression of an emotion, the experience of the emotion may still prevail and be left unresolved (Gross and John 2003). This aversive emotional state again can negatively affect later appraisals (discussed in Bodenhausen, Mussweiler, Gabriel and Moreno 2001, see also Lerner and Keltner 2000), such as appraisals about outgroups. Previous literature provides support for this notion. Expressive suppression is closely related to experiential avoidance (Kashdan, Barrios, Forsyth and Steger 2006; Su, Wei and Tsai 2014), which refers to unwillingness to experience unpleasant emotions, thoughts, bodily sensations and behavioral predispositions (Hayes, Wilson, Gifford, Follette and Strohsal 1996). Experiential avoidance forms part of a larger construct of psychological inflexibility, which has been shown to predict generalized prejudice (Levin, Luoma, Vilardaga, Lillis, Nobles and Hayes 2016). Another further possible mechanism relates to the individual's ability to cope with possible automatic prejudiced reactions; psychologically inflexible individuals may for example be more likely to act on the prejudiced beliefs (Levin, Luoma, Vilardaga, Lillis, Nobles and Hayes 2016). Expressive suppression has been linked to psychopathology (Aldao et al. 2010) displaced aggression (Scott et al. 2015) and self-reported aggressive behaviour (after controlling for trait anger) among men who have been exposed to interpersonal violence (Tull et al. 2007).
Burns et al. (2008) studied the causal effect of emotional suppression (which includes both expressive and experiential suppression) in heterosexual participants while watching a video about a gay couple. Individuals high in prejudice reported more positive emotions in the suppression group than in the control group, which the authors suggested indicated overcompensation in regulatory efforts due to lesser experience regulating emotions toward stereotyped targets. In the present study we, however, expected that individuals with a higher degree of habitual expressive suppression will experience more negative emotions in general, which will be reflected in more negative views toward out-groups. We based this expectation on other available research indicating that the use of suppression is associated with a larger degree of negative and smaller degree of positive emotions (Gross and; John 2003; Nezlek and Kuppens 2008; Balzarotti et al. 2010; ). In addition, Burns et al. (2008) measured the causal effect of suppression in response to a specific stimulus material, whereas we aimed to study trait expressive suppression in relation to general attitudes toward out-groups.

In sum, based on the previous literature, we proposed that individuals who habitually rely on expressive suppression are less able to neutralize negative emotional states compared to individuals who tend to use cognitive reappraisal. As a result, negative emotional states are more likely to prevail in these individuals. These negative emotions again influence the formation of attitudes toward out-groups, given the influence affective components have on cognition.

Emotion Dysregulation. Even when experiencing negative emotions, adaptive emotion regulation aims at modulating the emotional response, rather than eliminating it (Gratz and Roemer 2004), and thus allowing the individual to function well in a given context (Bridges et al. 2004). Cognitive reappraisal and expressive suppression both generally meet these criteria. Difficulties arise when the frequency and severity of maladaptive regulation increases. Emotion dysregulation refers to the inability to regulate emotional experiences, expressions and responses in regular settings (Linehan et al. 2007). Emotion dysregulation is a component and a risk factor of certain psychopathologies (CampbellSills and Barlow 2007; Aldao et al. 2010). Like expressive suppression, emotion dysregulation is associated with negative affect and increased aggression (see Roberton et al. 2012 for a review). Studies on the association between emotion dysregulation and out-group attitudes are limited in number. One study that taps into this field was conducted by Schlachter and Duckitt (2002). They found in a clinical sample that an avoidant-negativistic personality characteristic (consisting of features generally associated with emotion dysregulation; e.g. borderline, avoidant, negativistic) was indirectly, positively associated with prejudice, mediated via negative affective symptoms. 
Zipris, Pliskin, Canetti and Halperin (2019) conducted a study in the aftermath of the 2014 war in Gaza using a survey including emotion-inducing stimuli. They found that individuals who were exposed to political violence and had emotion dysregulation characteristics were more likely to have posttraumatic symptoms and negative emotions, and to support militant action and collateral damage (toward the out-group).

Due to the association between emotion dysregulation and negative affect, as well as the strong relationship between negative emotions and prejudice, we expected that emotion dysregulation is associated with increased levels of prejudice toward out-groups. Individuals who fail to effectively downregulate negative emotions (including emotions toward outgroups) would remain with higher levels of negative emotions and stronger negative emotional states. These negative emotions again influence subsequent appraisals, for example those of out-groups (Lerner and Keltner 2000). Individuals with more emotion dysregulation characteristics should, therefore, with a greater likelihood express negative attitudes toward out-groups.

Gender Differences. As mentioned previously, successful emotion regulation takes place in accordance with social norms. However, norms for acceptable emotion expression frequently differ for men and women (Fischer and Manstead 2000; see also Brody 2000). In fact, several studies have found that men tend to use expressive suppression more than women, whereas there are small or no gender differences in the use of cognitive reappraisal (e.g., Gross and John 2003; Rogier et al. 2017), although results are somewhat mixed (Tamres et al. 2002). A study by McRae et al. (2008) reported gender differences in the neural bases for cognitive appraisal. Women use both adaptive and maladaptive emotion regulation strategies to a larger degree than men (Nolen-Hoeksema and Aldao 2011). Concerning out-group attitudes, women also tend to report less prejudice than men (Akrami et al. 2000). Due to these reported gender differences in emotion regulation and out-group attitudes, we assessed whether our main analyses were influenced by gender in order to avoid generalizing a possibly gender-specific association to the whole population. We expected that the earlier research was reflected in our results, so that men reported more suppression and negative attitudes toward out-groups than women.

\section{The Current Study}

In sum, we proposed that emotion regulation and emotion dysregulation are associated with explicit attitudes toward different minority groups. Although most previous research has been conducted in conflict settings with attitudes toward specific antagonist groups as outcome measure, there is abundant literature from non-conflict settings supporting the association between emotions and prejudice more generally (Miller et al. 2004; Tapias et al. 2007; Kessler et al. 2010; Tenenbaum et al., 2018). Effective regulation of those (negative) emotions is, therefore, likely to attenuate, or even prevent, negative appraisals and attitudes toward out-groups (Gross et al. 2013).

We conducted a correlational study using an online survey to which we invited a random, population-based sample of Finns. We expected that:

1. Participants who rely predominantly on expressive suppression will have less favorable attitudes toward outgroups in general.

2. Participants who rely predominantly on cognitive reappraisal will have more favorable attitudes toward outgroups in general.

3. Participants who express emotion dysregulation characteristics will have less favorable attitudes toward outgroups in general.

Due to differences in emotion regulation and out-group attitudes between men and women as reported above, we also assessed whether the associations were moderated by gender. We also examined how self-identification with the out-groups moderated the associations.

Finally, we performed three exploratory analyses in order to guide future research questions: First, since part of emotion regulation can occur outside conscious control (Mauss et al. 2007), we investigated the associations between automatic emotion regulation and attitudes toward out-groups (Electronic Supplementary Material 1). Second, we wanted to explore whether the association between emotion regulation strategies would differ between sub-samples of out-groups. Lastly, we wanted to assess whether participants who rely more on cognitive reappraisal relative to expressive suppression have more favorable attitudes toward out-groups in general.

\section{Method}

\section{Participants and Demographics}

A random sample of 5000 Finnish-speaking citizens (1864 years) was drawn from the Population Register of Finland and we sent them invitation letters to participate in the study. A total of 307 participants $(6.1 \%)$ completed the whole survey, and $628(12.6 \%)$ of the invited participants entered the survey web page and/or completed the survey partially. The total number of participants who responded to the items included in the hypothesis testing was 320 . 


\section{Ethical Permission}

The study plan was approved by the Board for Research Ethics at Åbo Akademi University.

\section{Procedure}

We collected all self-report data online. In Finland, 93\% of 16-74 year-old individuals use the internet (Statistics Finland 2015). We sent the entire sample an invitation by post, stating that the recipient had been randomly selected to an anonymous, voluntary study about societal opinions and emotional experiences. The first page of the online survey described the anonymous, voluntary nature of the study and the data handling. Informed consent was obtained from all individual participants included in the study. The participants were told that they could participate in a draw of a cinema ticket.

\section{Measures}

Demographic Information We asked the participants for gender, age, marital status, residential region, mother tongue, highest level of education, and level of religiosity on a scale $(1=$ extremely religious, $10=$ extremely non-religious $)$. Demographic information is presented in Table 1.

Emotion Regulation Questionnaire (ERQ) We assessed emotion regulation using the 10-item Emotion Regulation Questionnaire (Gross and John 2003). ERQ measures the habitual use of cognitive reappraisal and expressive suppression. Answers to all items are given on a 7-point Likert scale ( $1=$ "strongly disagree", $7=$ "strongly agree"). The measure

Table 1 Demographic information

Complete responses $n(\%)$

\begin{tabular}{ll} 
Gender & \\
Female & $188(58.8)$ \\
Male & $131(40.9)$ \\
Age (years) & \\
$18-29$ & $103(32.2)$ \\
$30-39$ & $57(17.8)$ \\
$40-49$ & $54(16.9)$ \\
$50-59$ & $70(21.9)$ \\
above 60 & $36(11.3)$ \\
Highest level of education & \\
Primary school & $23(7.2)$ \\
High school & $53(16.6)$ \\
Vocational upper secondary & $77(24.1)$ \\
B.A. / Polytechnic & $97(30.3)$ \\
Master's degree or above & $70(21.9)$ \\
\hline
\end{tabular}

has been validated in European community samples (e.g. Enebrink et al. 2013; Balzarotti et al. 2010). We obtained the Finnish translation (Vuorela and Nummenmaa 2004) of the ERQ from the Stanford Psychophysiology Lab Resources web site (https://spl.stanford.edu/resources). A factor analysis of the Finnish translation (Westerlund and Santtila 2018) supported the expected two factor solution with item number 5 dropped due to low factor loadings. The cognitive reappraisal scale had a Cronbach's $\alpha$ of .74, and the expressive suppression scale .81 .

Difficulties in Emotion Regulation Scale (DERS-16) We measured emotion dysregulation using a 16-item version (Bjureberg et al. 2016) of the Difficulties in Emotion Regulation Scale (Gratz and Roemer 2004). The DERS-16 has five of the original six latent factors of DERS: Nonacceptance of Emotional Responses, Difficulties Engaging in Goal-Directed Behavior, Impulse Control Difficulties, Limited Access to Emotion Regulation Strategies, and Lack of Emotional Clarity (Gratz and Roemer 2004; Bjureberg et al. 2016; ). The scale has been validated in clinical and community samples (Bjureberg et al. 2016). The translation was gathered from an existing Finnish translation of the original DERS (Tapolaa et al. 2010).

A factor analysis (Westerlund and; Santtila 2018), supported the expected five factor model with two items (number 14 and 16) dropped. The subscales had adequate internal reliability (Cronbach's $\alpha=.70-.90)$.

Stress Measure We used a single-item stress measure to screen participants for experienced level of stress since we wanted to control for this factor, which may compromise otherwise adaptive emotion regulation. This measure has been employed in Finnish occupational health studies, and has shown satisfactory validity in different Finnish samples (Elo et al. 2003). The response was recorded on a 5-point Likert scale ("not at all" to "very much").

Attitudes Toward Out-Groups In line with Duckitt and Sibley's (2007) study, we compiled a list of 26 different sexual, ethnic, cultural, religious, health-related and political/ socioeconomic groups: Atheists, Christians, Muslims, Jews, migrants from the Middle East, migrants from Africa, rightwingers, feminists, left-wingers, Sami people, FinlandSwedes, Finland's Roma people, Russians, persons with high income, Romanian beggars, persons living on disability pension, housewives, the unemployed, gay persons, transgender persons, people with physical disability, elderly, sex workers, obese persons, persons with substance use disorder, and mental health patients. The participants recorded how negative or positive their general view on each group was on a Likert-type response scale, ranging from 1 ("very negative") to 7 ("very positive"). We summed the responses into a total score of 
acceptance. To control for the participants' own minority status, we asked participants to state whether they themselves identified as any of these out-groups.

Different out-groups may elicit different levels of perceived threat (Cottrell and; Neuberg 2005). For our exploratory analyses, we wanted to assess, whether emotion regulation was differentially associated with different out-groups. We explored the attitudes toward the 26 groups with an exploratory factor analysis (Electronic supplementary material 2). This revealed five latent constructs; ethnic out-groups (groups ethnically distinct from the majority of Finnish nationals), antinormative outgroups (groups generally seen as actively departing from the mainstream norms, e.g., atheists, transgender persons), crimeassociated out-groups (groups generally associated with crime; e.g., sex workers, persons with substance use disorder), privileged out-groups (groups generally seen as materially privileged), and internal differing out-groups (internal groups in the Finnish society, who may be perceived as differing from the mainstream, e.g., housewives, people with physical disability, and mental health patients).

Forced-Choice Test Given that the assessment of attitudes that violate existing social norms (like racism) is prone to social desirability bias (Krumpal 2013), six out-groups (FinlandSwedes, Migrants from developing countries, Muslims, Homosexuals, Unemployed, Disabled) were selected for a forced choice test for a comparison with the self-reported attitudes. We chose one group from each category of groups (i.e. sexual, ethnic, cultural, religious, health-related and socioeconomic groups). The forced-choice format prevents the participants from distorting their scores toward socially desirable answers since they are asked to choose one preferred group of two given options instead of scoring the groups more freely. This kind of questioning is likely to protect against desirable responding (Martin et al. 2002). Moreover, analyses of paired forced-choice data allows for interpreting outcomes on an interval scale (Kingdom and; Prins 2016) .

Automatic Emotion Regulation Since controlled emotion regulation requires considerable resources (Koole and Rothermund 2011) and situations requiring regulation of emotional responses occur constantly throughout the day, some of the emotion regulatory processes likely occur outside of the individual's awareness to reduce the costs of regulation (Mauss et al. 2007, see also Wang et al. 2017). In order to explore associations of automatic emotion regulation on outgroup attitudes we used a variant of the Implicit Association test (IAT; Greenwald et al. 1998); the emotion regulation IAT (ER-IAT; Mauss et al. 2006), which measures implicit evaluations of emotion regulation. However, the results from this measure were ambiguous and did not meaningfully complement the overall results. The description and the results from the ER-IAT are reported in the electronic supplementary material1.

\section{Statistical Analyses}

With a sample of 320 we had an .80 power to detect correlations as low as .16. No a priori power analysis was performed.

We conducted all analyses using SPSS 24.0, except for the analysis of the forced choice task, which was conducted with the prefmod-package (Hatzinger and Dittrich 2012) in R (R Core Team 2008). Moderation analyses were conducted with the PROCESS macro for SPSS (Hayes 2018). We explored the data to verify that the assumptions of the linear model were met. We explored linearity, independence of residuals and homoscedasticity graphically. To assess the effect of the extreme cases, we deleted four cases with both high Mahalanobis distances and high leverage, and repeated the regression analyses (Field 2013).

Hypothesis Testing To test the association of expressive suppression and cognitive reappraisal with attitudes toward outgroups, we created a total score reflecting individual acceptance of all out-groups. The associations between the ERQ subscales, the DERS-16 and the total score for acceptance of all outgroups were examined using a linear regression model. The moderation analyses to assess for the influence of gender and self-identification were conducted using the PROCESS macro (Hayes 2018), model 1, without centering the variables. We conducted the moderation analyses with standardized variables in order to obtain standardized regression coefficients.

We also tested the influence of eliminating extreme values and rerunning the analyses. Finally, there was a relatively large number of missing data, which carries a risk of reduction in statistical power and may lead to biased results. To address this, we repeated the hypothesis testing after performing multiple imputation to assess whether the analyses would yield similar conclusions as when restricted to the original data. We first conducted a missing values analysis, which indicated data missing mostly at random. Next, using SPSS's multiple imputation function, we generated 20 imputed datasets for the ERQ and DERS-16 items, the acceptance scores, as well as stress level, religiosity and age. We then conducted the regression analyses using z-scores of the variables in order to obtain pooled standardized regression coefficients.

Exploratory Testing In an explorative manner, we wanted to assess whether automatic emotion regulation was associated with the acceptance of out-groups. This analysis is reported in the electronic supplementary material 1.

We also explored whether the association between emotion regulation differed for different out-groups. We performed simple regression analyses where expressive suppression was entered as a predictor for acceptance of each of the five latent out-groups.

In addition, as previous literature has highlighted the importance of assessing the interaction of emotion regulation 
strategies (Aldao and; Nolen-Hoeksema 2012), we wanted to explore whether the balance between emotion regulation strategies influenced the outcome. Therefore, we created a score for the difference between individual levels of the two emotion regulation strategies. We created a difference variable by subtracting the expressive suppression score from the cognitive reappraisal score. We then used simple regression analysis to investigate its association with acceptance of all out-groups.

\section{Results}

\section{Descriptive Results}

Means, standard deviations for ERQ, DERS-16, the median for the stress measure and correlations among the measures are reported in Tables 2 and 3. The correlations between the ERQ (particularly the Suppression scale) and DERS-16 indicated partial overlap, but overall the scales seem to tap into different constructs. In addition, stress correlates significantly with DERS-16, indicating that stress may jeopardize adaptive emotion regulation. The mean acceptance scores and the results of the exploratory factor analysis are found in the electronic supplementary material 2 . The out-group preference scores from the forced-choice test corresponded largely with the self-reported acceptance scores. The preference scores are reported in the electronic supplementary material 3.

Demographic Factors and Emotion Regulation There was a significant correlation between education and the DERS scale $(r=-.12, p=.027)$, implying that lower level of education was associated with increased emotion dysregulation.

Table 2 Mean scores on the DERS-16 and ERQ subscales, and the stress measure

\begin{tabular}{|c|c|c|c|c|c|c|}
\hline & \multirow{2}{*}{\multicolumn{2}{|c|}{$\frac{\text { Women }}{(n=188)}$}} & \multirow{2}{*}{\multicolumn{2}{|c|}{$\frac{\text { Men }}{(n=131)}$}} & \multirow{2}{*}{\multicolumn{2}{|c|}{$\frac{\text { All }}{(n=320)}$}} \\
\hline & & & & & & \\
\hline & $M$ & $S D$ & $M$ & $S D$ & $M$ & $S D$ \\
\hline DERS-16 scale* & 27.44 & 9.84 & 26.41 & 8.63 & 27.04 & 9.36 \\
\hline GOALS & 9.92 & 4.04 & 9.35 & 3.65 & 9.70 & 3.89 \\
\hline STRATEGIES & 4.67 & 2.34 & 4.83 & 2.35 & 4.76 & 2.37 \\
\hline NONACCEPTANCE & 6.30 & 2.97 & 5.92 & 2.57 & 6.14 & 2.81 \\
\hline IMPULSE & 5.15 & 2.41 & 4.82 & 2.05 & 5.01 & 2.27 \\
\hline CLARITY & 3.56 & 1.26 & 3.50 & 1.34 & 3.54 & 1.30 \\
\hline ERQ Reappraisal & 4.59 & 1.06 & 4.20 & 1.00 & 4.43 & 1.05 \\
\hline ERQ Suppression & 2.93 & 1.08 & 3.62 & 1.22 & 3.22 & 1.19 \\
\hline Stress measure & 3 (Mdn) & & 3 (Mdn) & & 3 (Mdn) & \\
\hline
\end{tabular}

*Items 16 and 14 were excluded
Table 3 Correlations with DERS-16, ERQ subscales and the stress measure

\begin{tabular}{llll}
\hline & $\begin{array}{l}\text { Reappraisal } \\
r(p)\end{array}$ & $\begin{array}{l}\text { Suppression } \\
r(p)\end{array}$ & $\begin{array}{l}\text { Stress measure } \\
r(p)\end{array}$ \\
\hline DERS-16 scale & $.11(.057)$ & $.20(<.001)$ & $.42(<.001)$ \\
GOALS & $.12(.039)$ & $.09(.110)$ & $.38(<.001)$ \\
STRATEGIES & $-.01(.814)$ & $.26(<.001)$ & $.44(<.001)$ \\
NONACCEPTANCE & $.16(.004)$ & $.27(<.001)$ & $.33(<.001)$ \\
IMPULSE & $.04(.435)$ & $-.06(.265)$ & $.23(<.001)$ \\
CLARITY & $.13(.018)$ & $.24(<.001)$ & $.39(<.001)$ \\
ERQ Reappraisal & & & $.02(.685)$ \\
ERQ Suppression & & & $.04(.504)$ \\
\hline
\end{tabular}

Non-religiosity was positively correlated with expressive suppression $(r=.21, p<.001)$.

\section{Hypothesis Testing}

\section{Hypothesis 1 and 2: Associations between Emotion Regulation and Attitudes toward Out-Groups}

Next, we tested our hypothesis that expressive suppression is associated with less acceptance of out-groups and that cognitive reappraisal is associated with more acceptance of outgroups overall. The total score of acceptance of out-groups was predicted by expressive suppression, $b^{*}=-.17, p=.002$, $F(1,317)=9.57, R^{2}=.03, p=.002$. Self-identification with an out-group did not moderate this relationship $\left(b^{*}=0.13\right.$, $p=.410)$, nor did gender $\left(b^{*}=0.07, p=.529\right)$.

The acceptance of out-groups overall was not predicted by the use of cognitive reappraisal $\left(b^{*}=-.01, p=.935\right)$. There was no evidence of moderation by gender $\left(b^{*}=-0.05\right.$, $p=.681)$ nor self-identification $\left(b^{*}=0.31, p=.054\right)$.

\section{Hypothesis 3: Association between Emotion Dysregulation and Attitudes toward Out-groups}

We proceeded to examine our hypothesized association between emotion dysregulation and attitudes toward out-groups. There was no support for this association, $b^{*}=-.09, p=.098$, with $R^{2}=.01, F(1,317)=2.75$. There was also no evidence for moderation by gender $\left(b^{*}=-0.07, p=.556\right)$ or selfidentification $\left(b^{*}=0.13, p=.508\right)$.

Finally, we repeated the testing of the three hypotheses after performing multiple imputation using 20 imputed data sets to assess whether our results were influenced by the missing data. The pooled results supported our earlier results: (H1) Expressive suppression predicted decreased acceptance of outgroups at $b^{*}=-.18, p=.001$, and (H2) cognitive reappraisal did not predict acceptance toward out-groups, $b^{*}=$ $-.02, p=.749$. However, (H3) emotion dysregulation showed 
to have a negative association with out-group acceptance, $b *=-.12, p=.038$.

Exploratory Analyses We performed three explorative analyses. The description and the results of the first analysis which concerned the role of automatic emotion regulation is reported in the electronic supplementary material 1 . The results did not meaningfully complement the overall results and showed some ambiguity.

Our second exploratory question aimed to extend the results from the main analysis. We wanted to explore whether the associations between expressive suppression and out-groups differed between the five latent out-groups. We performed simple regression analyses where expressive suppression was entered as a predictor. Two significant associations emerged: expressive suppression predicted decreased acceptance of internal differing out-groups $\left(b^{*}=-.21, p<.001\right.$, with $R^{2}=.04, F(1$, $318)=14.36)$ and ethnic out-groups $\left(b^{*}=-.16, p=.005\right.$, with $\left.R^{2}=.03, F(1,318)=8.13\right)$.

Based on earlier literature concerning regulatory flexibility (Aldao and Nolen-Hoeksema 2012; Bonanno and Burton 2013; Otterpohl et al. 2016) we further wanted to assess how the relative distribution of the two emotion regulation strategies was related to out-group attitudes. We therefore explored whether a relatively higher degree of habitual cognitive reappraisal compared to expressive suppression would be associated with the attitudes toward all out-groups. There was a positive association between a relatively higher score of cognitive reappraisal than expressive suppression and acceptance of all out-groups $\left(b^{*}=.13, p=.018\right.$, with $R^{2}=.02, F(1$, $318)=5.7)$. This association was not moderated by gender $\left(b^{*}=-0.10, p=.378\right)$.

\section{Discussion}

We investigated the associations between emotion regulation strategies and emotion dysregulation on attitudes toward out-groups. We expected that participants with more habitual expressive suppression would have less favourable attitudes toward out-groups, and that habitual use of cognitive reappraisal would be associated with greater acceptance of out-groups. We also expected that participants with more emotion dysregulation would have less favourable attitudes toward out-groups.

In line with our first hypothesis, increased use of expressive suppression was associated with decreased acceptance of all out-groups. This reflects previous research, where expressive suppression has been linked for example to displaced aggression (Scott et al. 2015). On the other hand, the other form of generally maladaptive emotion regulation, emotion dysregulation, was not associated with the acceptance toward outgroups (the third hypothesis) before conducting the imputation. An interesting question, therefore, concerns which emotional components do play a role in intergroup attitudes. The findings suggest that the question may be about whether an emotion expression is inhibited or not. Gross and John (2003) suggest that expressive suppression may not be an effective means to reduce negative emotions if they are not the direct target of the regulation effort, leading to an accumulation of unresolved negative emotional experience. Emotion dysregulation, although not necessarily context-appropriate, may prevent such accumulation of negative affect through emotion expression. Gross and John (2003) showed that individuals who habitually used more expressive suppression were less satisfied with life, experienced more negative emotions, had lower self-esteem, less optimistic views on life and weaker social support.

All in all, the accumulated negative emotions together with the negative consequences of habitual expressive suppression could be a potential breeding ground for developing hostility toward out-groups. For example, individuals may make prejudiced evaluations of others to enhance their self-image (Fein and; Spencer 1997).

Nevertheless, the negative association between emotion dysregulation and out-group acceptance reached statistical significance in the analyses conducted after multiple imputation. Since emotion dysregulation has been linked to lack of perseverance (Fossati et al. 2014; Maxfield and Pepper 2018) it may be that individuals with less abilities to regulate negative states (for example fatigue) were more likely to discontinue the study. Future studies should further assess the relationship between emotion dysregulation and out-group attitudes.

We found no evidence for our second hypothesis that cognitive reappraisal would be related to attitudes toward outgroups. The result differs from earlier studies, in which cognitive reappraisal has been found to reduce out-group bias. Cognitive reappraisal strategies are effective in reducing negative out-group bias in contexts with greater polarization between groups and stronger negative intergroup emotions (for example in intractable conflicts; e.g., Halperin et al. 2013). It may be that these effects on prejudice are weaker in less emotional settings, in the absence of overt conflicts. This difference in context was reflected in the results reported by Steele et al. (2017). The authors found that another adaptive emotion regulation strategy, reflection, reduced bias and anger toward Muslims only after an intense intergroup threat (The Boston Marathon bombing), but not before. A possibility is that none of the out-groups in our study constituted in a current significant threat, which would elicit stronger negative emotions and be attenuated by regulatory efforts. A related possibility is that individuals experiencing less negative emotions are better able to use adaptive strategies like cognitive reappraisal.

A last point to highlight is that habitual emotion regulation can show variation over time, so that emotion regulation tends to become increasingly adaptive with age (Gross et al. 2006). 
Future studies should provide longitudinal data on emotion regulation and out-group attitudes to assess the stability of the reported associations.

\section{Exploratory Analyses}

Partly reflecting our main results about the use of expressive suppression and acceptance of out-groups, the exploratory findings suggested that a greater level of habitual cognitive reappraisal (relative to habitual expressive suppression) was positively associated with higher acceptance of out-groups. It is possible that greater acceptance toward out-groups emerges in the Finnish context after a certain threshold, that is, when the level of cognitive reappraisal is markedly higher than the normative level of cognitive reappraisal and the level of expressive suppression. This preliminary finding highlights the importance of studying emotion regulation strategies in relation to each other, as discussed for example by Bonanno and Burton (2013).

To further extend our understanding about the results on emotion regulation and the acceptance of out-groups, we performed a third exploratory analysis focusing on the role of emotion regulation on the acceptance of different sub-groups. A few indications emerged. The use of expressive suppression predicted negative attitudes toward internal differing groups and toward ethnic groups, but not toward antinormative, crime-associated or privileged groups. One plausible explanation to this finding could be the level of perceived threat. Cottrell and Neuberg (2005) found that the respondents perceived different out-groups threatening in a varying degree and the threat perception elicited functionally associated emotions. It is possible that the threat perception of ethnic and internal differing groups elicit a kind of aversive emotions that are less likely to be successfully regulated by individuals with a high degree of habitual suppression. Future studies should address the possible role of different levels of threat and compare the effects of emotion regulation strategies on the acceptance of different categories of out-groups.

The results of the current study highlight the potential of interventions targeting emotional processes in creating preventive programs and interventions that aim to decrease intergroup hostility. Such programs could be for example anti-prejudice programs in schools or interventions against intergroup violence in prisons. The programs could offer psychoeducation about the role of emotions in hostile out-group attitudes and training on adaptive emotion regulation strategies.

\section{Limitations}

There are several limitations in the present study that warrant discussion. The response rate was low. This may partly be due to the fact that no reminder letters were sent. Further, it is possible that some systematic factors were associated with participation, which increases the risk for a biased sample. The final sample did not, however, differ markedly from the population on the whole (OECD 2013; Statistics Finland 2017). The sample consists somewhat more of women (around $+7 \%$ ) than the overall population, and it is more educated (8-10\% differences, depending on education level; OECD 2013). The largest percentual differences in age groups in the sample compared to the general population is around $5 \%$.

The survey was completed online, which limited our control over the testing situation. The emotion regulation and the attitudes toward out-groups were measured with self-report, and are vulnerable to desirability bias. Measurement bias may also be an issue regarding the measures on explicit emotion regulation. Accurate self-report of emotion regulation -and likely the emotion regulation skills themselves requires introspective and metacognitive abilities. There may be significant variation in such abilities among the participants. The current study should, therefore, be replicated using objective measures of emotion regulation, such as physiological measures.

As previously mentioned, appraisals can be affected by several non-affective factors (Halperin et al. 2011), which were not thoroughly assessed in our study. Cultural factors could affect for example agency appraisals. In a study by Imada and Elsworth (2011), people from an individualistic culture were more likely to credit successes to themselves and blame external factors for failures, whereas the tendency for a person from a collectivistic culture was the opposite. Situational factors such as how motivationally relevant the situation is to the person (Smith and; Kirby 2011) also affect interpretations. Intersectionality is also relevant, e.g. if people interpret that they are treated differentially based on one or several of their social identities (Wang et al. 2011). Further influencing factors are personality factors such as level of authoritarianism, and socio-economic status (Halperin et al. 2011), which for example may influence how threatening a person appraises a situation.

Lastly, a number of variables, which might influence the outcome variables such as the familiarity and closeness to representatives of the included out-groups, were not assessed in the current study. There is also a possibility of hypothesis guessing, i.e. that the participants may have guessed the intent of the study and altered their responding accordingly. Relatedly, the study did not include a measure on socially desirable responding. It still needs to be tested how such variables might modulate the associations found in the present study.

\section{Conclusion}

Increased use of expressive suppression was associated with decreased acceptance of out-groups. Emotion dysregulation 
and cognitive reappraisal were not associated with attitudes toward out-groups, although after multiple imputation, an association between emotion dysregulation and out-group attitudes emerged. We found some preliminary indications for that relatively high cognitive reappraisal (over expressive suppression) was positively associated with acceptance of outgroups. This should be further tested in future studies. By highlighting the role of emotional components in overall intergroup attitudes, the results of the present study are applicable in programs aiming to increase intergroup acceptance and in clinical settings, for example in interventions with individuals who have engaged in intergroup conflicts.

Funding Information Open access funding provided by Abo Akademi University (ABO).

\section{Compliance with Ethical Standards}

Conflict of Interest The authors declare that they have no conflict of interest.

Open Access This article is distributed under the terms of the Creative Commons Attribution 4.0 International License (http:// creativecommons.org/licenses/by/4.0/), which permits unrestricted use, distribution, and reproduction in any medium, provided you give appropriate credit to the original author(s) and the source, provide a link to the Creative Commons license, and indicate if changes were made.

\section{References}

Akrami, N., Ekehammar, B., \& Araya, T. (2000). Classical and modern racial prejudice : A study of attitudes toward immigrants in Sweden. European Journal of Social Psychology, 30, 521-532. https://doi. org/10.1002/1099-0992(200007/08)30:4<521::AID-EJSP5>3.0. $\mathrm{CO} ; 2-\mathrm{N}$.

Aldao, A. (2013). The future of emotion regulation research: Capturing context. Perspectives on Psychological Science, 8(2), 155-172. https://doi.org/10.1177/1745691612459518.

Aldao, A., \& Nolen-Hoeksema, S. (2012). When are adaptive strategies most predictive of psychopathology? Journal of Abnormal Psychology, 121(1), 276-281. https://doi.org/10.1037/a0023598.

Aldao, A., \& Nolen-Hoeksema, S. (2013). One versus many: Capturing the use of multiple emotion regulation strategies in response to an emotion-eliciting stimulus. Cognition and Emotion, 27(4), 753-760. https://doi.org/10.1080/02699931.2012.739998.

Aldao, A., Nolen-Hoeksema, S., \& Schweizer, S. (2010). Emotionregulation strategies across psychopathology: A meta-analytic review. Clinical Psychology Review. https://doi.org/10.1016/j.cpr. 2009.11.004

Alkoby, A., Halperin, E., Tarrasch, R., \& Levit-Binnun, N. (2017). Increased support for political compromise in the israelipalestinian conflict following an 8-week mindfulness workshop. Mindfulness. https://doi.org/10.1007/s12671-017-0710-5.

Allport, G. W. (1985). The nature of prejudice. Reading, MA: AddisonWesley.

Balzarotti, S., John, O. P., \& Gross, J. J. (2010). An Italian adaptation of the emotion regulation questionnaire. European Journal of
Psychological Assessment, 26, 61-67. https://doi.org/10.1027/ 1015-5759/a000009.

Bjureberg, J., Ljótsson, B., Tull, M. T., Hedman, E., Sahlin, H., Lundh, L. G., et al. (2016). Development and validation of a brief version of the difficulties in emotion regulation scale: The DERS-16. Journal of Psychopathology and Behavioral Assessment, 38, 284-296. https://doi.org/10.1007/s10862-015-9514-x.

Blanchette, I., \& Richards, A. (2010). The influence of affect on higher level cognition: A review of research on interpretation, judgement, decision making and reasoning. Cognition \& Emotion, 24(4), 561595. https://doi.org/10.1080/02699930903132496.

Bodenhausen, G. V., Mussweiler, T., Gabriel, S., \& Moreno, K. N. (2001). Affective influences on stereotyping and intergroup relations. Handbook of Affect and Social Cognition, 319-343. https:// doi.org/10.1177/1368430201041002.

Bonanno, G. A., \& Burton, C. L. (2013). Regulatory flexibility: An individual differences perspective on coping and emotion regulation. Perspectives on Psychological Science, 8(6), 591-612. https://doi. org/10.1177/1745691613504116.

Bridges, L. J., Denham, S. A., \& Ganiban, J. M. (2004). Definitional issues in emotion regulation research. Child Development, 75 , 340-345.

Brody, L. R. (2000). The socialization of gender differences in emotional expression: Display rules, infant temperament, and differentiation. In A. H. Fischer (Ed.), Gender and emotion: Social psychological perspectives (pp. 24 47). Cambridge: Cambridge University Press. https://doi.org/10.1017/CBO9780511628191.003.

Burns, K. C., Isbell, L. M., \& Tyler, J. M. (2008). Suppressing emotions toward stereotyped targets: The impact on willingness to engage in contact. Social Cognition, 26(3), 276-287. https://doi.org/10.1521/ soco.2008.26.3.276.

Campbell-Sills, L., \& Barlow, D. H. (2007). Incorporating emotion regulation into conceptualizations and treatments of anxiety and mood disorders. In J. J. Gross (Ed.), Handbook in emotion regulation (pp. 542-559). New York: The Guilford Press.

Cottrell, C. A. A., \& Neuberg, S. L. L. (2005). Different emotional reactions to different groups: A sociofunctional threat-based approach to "prejudice". Journal of Personality and Social Psychology, 88(5), 770-789. https://doi.org/10.1037/0022-3514.88.5.770.

Duckitt, J., \& Sibley, C. G. (2007). Right wing authoritarianism, social dominance orientation and the dimensions of generalized prejudice. European Journal of Personality, 21, 113-130. https://doi.org/10. 1002/per.614.

Elo, A. L., Leppänen, A., \& Jahkola, A. (2003). Validity of a single-item measure of stress symptoms. Scandinavian Journal of Work, Environment and Health, 29, 444-451. https://doi.org/10.5271/ sjweh. 752 .

Enebrink, P., Björnsdotter, A., \& Ghaderi, A. (2013). The emotion regulation questionnaire: Psychometric properties and norms for Swedish parents of children aged 10-13 years. Europe's Journal of Psychology, 9, 289-303. https://doi.org/10.5964/ejop.v9i2.535.

Fein, S., \& Spencer, S. J. (1997). Prejudice as self-image maintenance: Affirming the self through derogating others. Journal of Personality and Social Psychology, 73, 31-44.

Field, A. (2013). Discovering statistics using IBM SPSS statistics -and sex and drugs and rock " $n$ " roll (4th ed.). London: SAGE Publications Ltd.

Fischer, A. H., \& Manstead, A. S. R. (2000). The relation between gender and emotions in different cultures. In A. H. Fischer (Ed.), Gender and emotion: Social psychological perspectives (pp. 71-94). New York: Cambridge University Press.

Fossati, A., Gratz, K.L, Maffei, C. \& Borroni, S. (2014). Impulsivity dimensions, emotion dysregulation, and borderline personality disorder features among Italian nonclinical adolescents. Borderline Personality Disorder and Emotion Dysregulation, 1(5). https://doi. org/10.1186/2051-6673-1-5. 
Gratz, K. L., \& Roemer, L. (2004). Multidimensional assessment of emotion regulation and dysregulation: Development, factor structure, and initial validation of the dif culties in emotion regulation scale. Journal of Psychopathology and Behavioural Assessment, 26, 41-54.

Greenwald, A. G., McGhee, D. E., \& Schwartz, J. L. K. (1998). Measuring individual differences in implicit cognition: The implicit association test. Journal of Personality and Social Psychology, 74, 1464-1480. https://doi.org/10.1037/0022-3514.74.6.1464.

Gross, J. J. (1998). The emerging field of emotion regulation: An integrative review. Review of General Psychology, 2, 271-299. https:// doi.org/10.1037/1089-2680.2.3.271.

Gross, J. J., \& John, O. P. (2003). Individual differences in two emotion regulation processes: Implications for affect, relationships, and wellbeing. Journal of Personality and Social Psychology, 85, 348-362. https://doi.org/10.1037/0022-3514.85.2.348.

Gross, J. J., Richards, J. M., \& John, O. P. (2006). Emotion regulation in everyday life. In D. K. Snyder, J. Simpson, \& J. N. Hughes (Eds.), Emotion regulation in couples and families: Pathways to dysfunction and health (pp. 13-35). Washington, DC: American Psychological Association.

Gross, J. J., Halperin, E., \& Porat, R. (2013). Emotion regulation in intractable conflicts. Current Directions in Psychological Science, 22, 423-429. https://doi.org/10.1177/0963721413495871.

Halperin, E., \& Gross, J. J. (2010). Intergroup anger in intractable conflict: Long-term sentiments predict anger responses during the Gaza war. Group Processes \& Intergroup Relations, 14(4), 477-488. https://doi.org/10.1177/1368430210377459.

Halperin, E., \& Gross, J. J. (2011). Emotion regulation in violent conflict: Reappraisal, hope, and support for humanitarian aid to the opponent in wartime. Cognition \& Emotion, 25, 1228-1236.

Halperin, E., Sharvit, K., \& Gross, J. (2011). Emotion and emotion regulation in intergroupconflict: An appraisal-based framework. In D. Bar-Tal (Ed.), Intergroup conflicts and their resolution (pp. 1-37). New York: Psychology Press. https://doi.org/10.4324/ 9780203834091.

Halperin, E., Porat, R., Tamir, M., \& Gross, J. J. (2013). Can emotion regulation change political attitudes in intractable conflicts? From the laboratory to the field. Psychological Science, 24, 106-111. https://doi.org/10.1177/0956797612452572.

Halperin, E., Pliskin, R., Saguy, T., Liberman, V., \& Gross, J. J. (2014). Emotion regulation and the cultivation of political tolerance: Searching for a new track for intervention. Journal of Conflict Resolution, 58, 1110-1138. https://doi.org/10.1177/ 0022002713492636.

Hatzinger, R., \& Dittrich, R. (2012). Prefmod: An R package for modeling preferences based on paired comparisons, rankings, or ratings. Journal of Statistical Software, 48(10), 1-31.

Hayes, A. F. (2018). Introduction to mediation, moderation, and conditional process analysis : A regression-based approach (2nd ed.). New York: Guilford Press.

Hayes, S. C., Wilson, K. G., Gifford, E. V., Follette, V. M., \& Strosahl, K. D. (1996). Experiential avoidance and behavioral disorders a functional dimensional approach to diagnosis and treatment comparing Syndromal and functional classification. Journal of Consulting and Clinical Psychology, 64, 1152-1168.

Imada, T., \& Ellsworth, P. C. (2011). Proud Americans and lucky Japanese: Cultural differences in appraisal and corresponding emotion. Emotion, 11(2), 329-345. https://doi.org/10.1037/a0022855.

Izard, C. E. (2010). The many meanings/aspects of emotion: Definitions, functions, activation, and regulation. Emotion Review. https://doi. org/10.1177/1754073910374661.

Kashdan, T. B., Barrios, V., Forsyth, J. P., \& Steger, M. F. (2006). Experiential avoidance as a generalized psychological vulnerability: Comparisons with coping and emotion regulation strategies.
Behaviour Research and Therapy, 44, 1301-1320. https://doi.org/ 10.1016/j.brat.2005.10.003.

Kessler, T., Mummendey, A., Funke, F., Brown, R., Binder, J., Zagefka, H., et al. (2010). We all live in Germany but ... Ingroup projection, group-based emotions and prejudice against immigrants. European Journal of Social Psychology, 40, 985997. https://doi.org/10.1002/ejsp.

Kingdom, F., \& Prins, N. (2016). Psychophysics: A practical introduction: Second Edition. London: Academic Print.

Koole, S. L., \& Rothermund, K. (2011). "I feel better but I don't know why": The psychology of implicit emotion regulation. Cognition \& Emotion, 25(3), 389-399. https://doi.org/10.1080/02699931.2010. 550505.

Krumpal, I. (2013). Determinants of social desirability bias in sensitive surveys: A literature review. Quality and Quantity, 47, 2025-2047. https://doi.org/10.1007/s11135-011-9640-9.

Lee, J. J., Sohn, Y., \& Fowler, J. H. (2013). Emotion regulation as the Foundation of Political Attitudes: Does reappraisal decrease support for conservative policies? PLoS ONE, 8(12). https://doi.org/10. 1371/journal.pone.0083143.

Lerner, J. S., \& Keltner, D. (2000). Beyond valence: Toward a model of emotion-specific influences on judgement and choice. Cognition and Emotion, 14, 473-493.

Levin, M. E., Luoma, J. B., Vilardaga, R., Lillis, J., Nobles, R., \& Hayes, S. C. (2016). Examining the role of psychological inflexibility, perspective taking, and empathic concern in generalized prejudice. Journal of Applied Social Psychology, 46, 180-191.

Linehan, M. M., Bohus, M., \& Lynch, T. R. (2007). Dialectical behavior therapy for pervasive emotion dysregulation: Theoretical and practical underpinnings. In J. J. Gross (Ed.), Handbook of emotion regulation (pp. 581-605). New York: Guilford Press.

Martin, B. A., Bowen, C. C., \& Hunt, S. T. (2002). How effective are people at faking on personality questionnaires? Personality and Individual Differences, 32(2), 247-256. https://doi.org/10.1016/ S0191-8869(01)00021-6.

Mauss, I. B., Evers, C., Wilhelm, F. H., \& Gross, J. J. (2006). How to bite your tongue without blowing your top: Implicit evaluation of emotion regulation predicts affective responding to anger provocation. Personality and Social Psychology Bulletin, 32(5), 589-602. https:// doi.org/10.1177/0146167205283841.

Mauss, I. B., Bunge, S. A., \& Gross, J. J. (2007). Automatic emotion regulation. Social and Personality Psychology Compass, 1(1), 146167. https://doi.org/10.1111/j.1751-9004.2007.00005.x.

Maxfield, B. L., \& Pepper, C. M. (2018). Impulsivity and response latency in non-suicidal self-injury: The role of negative urgency in emotion regulation. Psychiatric Quarterly, 89, 417-426. https://doi.org/ 10.1007/s11126-017-9544-5.

McRae, K., Ochsner, K. N., Mauss, I. B., Gabrieli, J. J. D., \& Gross, J. J. (2008). Gender differences in emotion regulation: An fMRI study of cognitive reappraisal. Group Processes \& Intergroup Relations, 11(2), 143-162. https://doi.org/10.1177/1368430207088035.

Miller, D. A., Smith, E. R., \& Mackie, D. M. (2004). Effects of intergroup contact and political predispositions on prejudice: Role of intergroup emotions. Group Processes \& Intergroup Relations, 7(3), 221-237.

Moors, A., Ellsworth, P. C., Scherer, K. R., \& Frijda, N. H. (2013). Appraisal theories of emotion: State of the art and future development. Emotion Review, 5(2), 119-124. https://doi.org/10.1177/ 1754073912468165.

Nezlek, J. B., \& Kuppens, P. (2008). Regulating positive and negative emotions in daily life. Journal of Personality, 76, 561-580. https:// doi.org/10.1111/j.1467-6494.2008.00496.x.

Nolen-Hoeksema, S., \& Aldao, A. (2011). Gender and age differences in emotion regulation strategies and their relationship to depressive symptoms. Personality and Individual Differences, 51(6), 704708. https://doi.org/10.1016/j.paid.2011.06.012. 
OECD. (2013). Education at a glance 2013 Finland country note. Retrieved from www.oecd.org. Accessed date 23 October 2018.

Otterpohl, N., Schwinger, M., \& Wild, E. (2016). Exploring the interplay of adaptive and maladaptive strategies: Prevalence and functionality of anger regulation profiles in early adolescence. Journal of Early Adolescence, 36(8), 1042-1069. https://doi.org/10.1177/ 0272431615593174 .

Pliskin, R., Halperin, E., Bar-Tal, D., \& Sheppes, G. (2018). When ideology meets conflict-related content: Influences on emotion generation and regulation. Emotion, 18(2), 159-170. https://doi.org/10. 1037/emo0000317.

R Development Core Team, R. F. F. S. C. (2008). R: A language and environment for statistical computing. Vienna Austria R Foundation for Statistical Computing, 1(10).

Raio, C. M., Orederu, T. A., Palazzolo, L., Shurick, A. A., \& Phelps, E. A. (2013). Cognitive emotion regulation fails the stress test. Proceedings of the National Academy of Sciences, 110, 1513915144. https://doi.org/10.1073/pnas.1305706110.

Roberton, T., Daffern, M., \& Bucks, R. S. (2012). Emotion regulation and aggression. Aggression and Violent Behavior, 17, 72-82. https://doi. org/10.1016/j.avb.2011.09.006.

Rogier, G., Garofalo, C., \& Velotti, P. (2017). Is emotional suppression always bad? A matter of flexibility and gender differences. Current Psychology, 1-10. https://doi.org/10.1007/s12144-017-9623-7.

Scherer, K. R. (2009). The dynamic architecture of emotion: Evidence for the component process model. Cognition \& Emotion, 23(7), 13071351. https://doi.org/10.1080/02699930902928969.

Schlachter, A., \& Duckitt, J. (2002). Psychopathology, authoritarian attitudes, and prejudice. South Africa Journal of Psychology, 32(2), 18. https://doi.org/10.1177/008124630203200201.

Scott, J. P., Dilillo, D., Maldonado, R. C., \& Watkins, L. E. (2015). Negative urgency and emotion regulation strategy use: Associations with displaced aggression. Aggressive Behavior, 41(5), 502-512. https://doi.org/10.1002/ab.21588.

Smith, C. A., \& Kirby, L. D. (2009). Putting appraisal in context: Toward a relational model of appraisal and emotion. Cognition and Emotion, $23,1352-1372$

Statistics Finland. (2015). Suomen virallinen tilasto (SVT): Väestön tietoja viestintätekniikan käyttö [Finland's official statistic: The population's use of information and communication technology]. Helsinki: Tilastokeskus. Retrieved from: http:/www.stat.fi/til/sutivi/2015/ sutivi 2015 2015-11-26 tie 001 fi.html

Statistics Finland. (2017). Väestö (Population). Retrieved from http:// www.tilastokeskus.fi/tup/suoluk/suoluk vaesto.html

Steele, R. R., Rovenpor, D. R., Lickel, B., \& Denson, T. F. (2017). Emotion regulation and prejudice reduction following acute terrorist events: The impact of reflection before and after the Boston Marathon bombings. Group Processes \& Intergroup Relations, 114. https://doi.org/10.1177/1368430217706182.

Su, J. C., Wei, M., \& Tsai, H. T. (2014). Running away from unwanted feelings: Culture matters. Cognition and Emotion, 28, 1313-1327. https://doi.org/10.1080/02699931.2014.881322.

Tamres, L. K., Janicki, D., \& Helgeson, V. S. (2002). Sex differences in coping behavior : A meta-analytic review and an examination of relative coping. Personality and Social Psychology Review, 6, 2-30.
Tapias, M. P., Glaser, J., Keltner, D., Vasquez, K., \& Wickens, T. (2007). Emotion and prejudice: Specific emotions toward outgroups. Group Processes \& Intergroup Relations, 10(1), 27-39. https://doi.org/10. 1177/1368430207071338.

Tapolaa, V., Lappalainen, R., \& Wahlström, J. (2010). Brief intervention for deliberate self harm: An exploratory study. Suicidology Online, $1,95-108$.

Tenenbaum, H. R., Capelos, T., Lorimer, J., \& Stocks, T. (2018). Positive thinking elevates tolerance: Experimental effects of happiness on adolescents' attitudes toward asylum seekers. Clinical Child Psychology and Psychiatry, 23(2), 346-357. https://doi.org/10. 1177/1359104518755217.

Tull, M. T., Jakupcak, M., Paulson, A., \& Gratz, K. L. (2007). The role of emotional inexpressivity and experiential avoidance in the relationship between posttraumatic stress disorder symptom severity and aggressive behavior among men exposed to interpersonal violence. Anxiety, Stress and Coping, 20(4), 337-351. https://doi.org/10.1080/ 10615800701379249.

Vieten, U. M., \& Poynting, S. (2016). Contemporary far-right racist populism in Europe. Journal of Intercultural Studies, 37(6), 533-540. https://doi.org/10.1080/07256868.2016.1235099.

Vuorela, M., \& Nummenmaa, L. (2004). Experienced emotions, emotion regulation and student activity in a web-based learning environment. European Journal of Psychology of Education, 19, 423-436. https:// doi.org/10.1007/BF03173219.

Wang, J., Leu, J., \& Shoda, Y. (2011). When the seemingly innocuous "stings": Racial microaggressions and their emotional consequences. Personality and Social Psychology Bulletin, 37(12), $1666-1678$.

Wang, H. Y., Xu, G. Q., Ni, M. F., Zhang, C. H., Sun, X. P., Chang, Y., \& Zhang, B. W. (2017). Neural mechanisms of implicit cognitive reappraisal: Preceding descriptions alter emotional response to unpleasant images. Neuroscience, 347, 65-75. https://doi.org/10. 1016/j.neuroscience.2017.01.047.

Westerlund, M., \& Santtila, P. (2018). A Finnish adaptation of the emotion regulation questionnaire (ERQ) and the difficulties in emotion regulation scale (DERS-16). Nordic Psychology, 70, 304-323. https://doi.org/10.1080/19012276.2018.1443279.

Wolgast, M., Lundh, L.-G., \& Viborg, G. (2011). Cognitive reappraisal and acceptance: An experimental comparison of two emotion regulation strategies. Behaviour Research and Therapy, 49(12), 858866. https://doi.org/10.1016/j.brat.2011.09.011.

Zawadzki, B. (1948). Limitations of the scapegoat theory of prejudice. The Journal of Abnormal and Social Psychology, 43, 127-141.

Zipris, I., Pliskin, R., Canetti, D., \& Halperin, E. (2019). Exposure to the 2014 Gaza war and support for militancy: The role of emotion dysregulation. Personality and Social Psychology Bulletin, 45, 965977. https://doi.org/10.1177/0146167218805988.

Publisher's note Springer Nature remains neutral with regard to jurisdictional claims in published maps and institutional affiliations. 